\title{
Science policy must keep pace with science
}

For the past few years the Organisation for Economic Cooperation and Development (OECD) has been brooding on the so-called research system-the network of organisations which support and do scientific research, be it fundamental or applied, military or ecological. Eight European countries, Canada and the United States have been subjected to an examination of how they run their science, and the last report rounding off the series with conclusions and a string of recommendations is recently out. At least, the book version is newly published - it has been circulating in samizdat in varying degrees of confidentiality for the best part of a year (The Research System, 3; OECD Paris, £3.80).

The problem with reports from international organisations is that they are bound to be toothless, and therefore less than compulsory reading. Nothing fixes the mind more when reading a White Paper than the knowledge that the author is committed to converting proposals into reality within a few months. An OECD document can be dismissed as reflecting the opinions of a staff with necessarily limited access to information and no powers to implement proposals. To do so with this document, however, would be to fail to appreciate the value of a relaxed international perspective on the remarkable phenomenon of the turning of various scientific tides around 1970 and the attempts (and sometimes failures) of scientists and administrators to cope with the new scenery of the 1970s. The report, and particularly the conclusions, dry as they may seem, could with profit be read by any scientist who worries about what he will be doing in five years time.

Part of the OECD's theme is that the pursuit of major strategic objectives, particularly in defence, nuclear energy and space, started to falter in the late 1960s and since then the main running has been taken up by matters of more common concern both nationally and internationally, such as the environment, community services and health. Few would doubt this, though for good measure graphs are included which show among other things that in the past ten years public expenditure on health research and development at least doubled in real terms whereas defence expenditure remained static. Indeed in Canada research and development on health has risen eight-fold in ten years, and is now as great as research and development expenditure on defence.

With the decline of the "major strategic objective" as a dominant force in science, however, have the mechanisms for evolving science policy changed accordingly? For the OECD sees several sacred concepts of the 1960 s as being no longer accepted as axiomatic.

- The Humboldt principle that teaching and research are inseparable "may have done more harm than good" by prejudicing the evolution of research and its vitality as much as prejudicing teaching.

- The search for a 'Magic Figure' for the percentage of
GNP spent on research and development has lost much of its meaning with the manifest scientific and technological successes of small-spending countries.

- The idea that fundamental science should have a certain percentage (often quoted as 10\%) of total expenditure on research and development devoted to it is 'little more than folklore'.

- The concept of peer selection for the disposition of money for research to a principal investigator "does not seem to have guaranteed the quality of research so much as it has consolidated its regular advance along beaten tracks".

By this analysis the scientific community found itself caught short by the change in priorities imposed on it and tended to rationalise the swing away from the hard sciences among students as "an easy and even amateurish choice inevitable in a mass university open to all". But maybe these young people had a premonition of the future requirements of society; if sustained long enough the premonition would become self-fulfilling.

The changes that science and technology have undergone and will continue to undergo are not such as will throw thousands out of work, and they are not immediately detectable by scanning the scientific literature for a discontinuity of some sort. Nevertheless they are profound in that the earliest effects appear amongst science's latest recruits-and science has traditionally depended on the young. They are also profound in that they move science into a more political environment and a world in which there are nothing but complex answers to the simplest of questions. Can science-policymaking cope with the transition and can the sort of institutions established under past policymaking (or lack of it) fulfil a continued useful role? Two of the OECD's points deserve more debate in the British context.

First, the arena in which the support for and use of science is discussed should be broadened to permit the participation of "the young, the quiet, the not-so-eminent". Academics, foundations and learned societies should be encouraged to "equip themselves with the means for participation". Second, the countries which OECD believes have tried best to adapt to new dimenisions have been those where ministries have been constituted with wide responsibilities for "coordinating and animating scientific effont"-Science Ministries, without other sectoral responsibilities.

The need for a science ministry is not immediately apparent in Britain, especially at a time when many scientists are still readjusting to the organisational changes of the last three years. But the need for somewhere to discuss how the management of science should be conducted in 1980 is all too obvious; not in a oneday meeting but as a regular open forum where the young, quiet and not-so-eminent can learn and be heard. Council for Science and Society, please note. 